Relations industrielles

Industrial Relations

\title{
Statistiques des relations de travail
}

Volume 4, numéro 9, mai 1949

URI : https://id.erudit.org/iderudit/1023966ar

DOI : https://doi.org/10.7202/1023966ar

Aller au sommaire du numéro

Éditeur(s)

Département des relations industrielles de l’Université Laval

\section{ISSN}

0034-379X (imprimé)

1703-8138 (numérique)

Découvrir la revue

Citer cet article

(1949). Statistiques des relations de travail. Relations industrielles / Industrial Relations, 4(9), 89-89. https://doi.org/10.7202/1023966ar

Tous droits réservés @ Département des relations industrielles de l’Université Laval, 1949
Ce document est protégé par la loi sur le droit d'auteur. L’utilisation des services d'Érudit (y compris la reproduction) est assujettie à sa politique d'utilisation que vous pouvez consulter en ligne.

https://apropos.erudit.org/fr/usagers/politique-dutilisation/ 


\section{STATISTIQUES DES RELATIONS DE TRAVAIL}

A titre documentaire, nous sommes heureux de donner quelques statistiques sur les relations de travail dans la Province de Québec pour le mois de nai 1949. Ces statistiques nous sont gracieusement fournies par le ministère du Travail.

1. Reconnaissances syndicales. -24 requêtes en reconnaissance syndicale ont été présentées; sur ce nombre 6 ont été agréées et le certificat d'accréditation émis dans chaque cas; 1 requête a été refusée; 2 certificats ont été révoqués; 4 votes ont été tenus.

Si on tient compte des 24 requêtes reçues durant le mois et des requêtes antérieures dont on n'avait pas disposé, au total 60 requêtes pour certification ont été considérées; celles-ci visaient 1,594 salariés.

Par ailleurs, la Commission de relations ouvrières a référé au ministère du travail 36 requêtes en conciliation en vue d'aider les parties à conclure une convention collective. 5 enquêtes ont été initiées sur des cas de congédiements, intimidation et contre-grèves. La Commission a tenu 16 auditions et n'a eu à accorder aucune autorisation de poursuivre.

2. Conventions collectives. - Au cours de mai 1949, 38 conventions collectives ont été déposées à la Commission, dont 16 en vertu de l'article 19 de la Loi des relations ouvrières et 22 en vertu de l'article 19-A. Ces conventions couvrent 5,165 salariés. - 30 conventions intéressent les établissements industriels; 1 , les établissements commerciaux; 5 , des services privés; 2 , des services publics.

En décomposant le dépôt des conventions selon l'affiliation syndicale, on note les résultats suivants:

17 conventions intéressant 2,690 salariés ont été déposées par des syndicats affiliés à la Confédération des Travailleurs catholiques du Canada, inc.;

4 conventions affectant 124 salariés ont été déposées par des unions affiliées au Congrès canadien du Travail;

9 conventions affectant 1,972 salariés ont été déposées par des unions affiliées au Congrès des Métiers et du Travail du Canada;
Enfin, 5 conventions affectant 1,086 salariés ont été déposées par des syndicats indépendants incorporés et 3 affectant 379 salariés, par des syndicats indépendants non incorporés.

Au 31 mai, 1949, les statistiques de la Commission de relations ouvrières indiquent que 1,204 conventions collectives sont en vigueur affectant 190,360 salariés dans la Province.

3. Arbitrage. - 28 tribunaux d'arbitrage étaient en fonction au ler mai 1949. Durant le mois, 3 nouveaux tribunaux ont été formés. Au cours de la même période, 7 sentences arbitrales ont été rendues. Il y avait donc au 31 mai 1949, 24 tribunaux d'arbitrage en fonction, dont 5 au titre des services publics et 19 à celui des entreprises privées.

\section{THĖSES SUR LES RELATIONS INDUS. TRIELLES PRÉSENTÉES POUR L'OBSTEN. TION DE LA MAITRISE EN SCIENCES SOCIALES}

BELANGER, abbé Ovila, La formation professionnelle dans les centres d'apprentissage.

DION, Denys, Etude comparative des lois des syndicats professionnels de France et de Québec.

GOSSELIN, Jean-Yves, Enquête sur l'application du décret relatif à l'industrie de la boulangerie de Québec.

LIZOTTE, Jean, Monographie d'un service du personnel dans un magasin d rayon.

PEPIN, Marcel, L'organisation ouvrière dans l'industrie textile du Québec.

POIRIER, Chs-Edouard, Etude sur le décret relatif au commerce de l'alimentation au détail de Québec.

RICARD, Louise, Monographie industrielle du centre médical de la Compagnie Dominion Corset Ltd., Québec.

SINCENNES, Aldège, Etude sur le décret du commerce de gros de l'alimentation dans la région de Québec.

THERIEN, Chs-Edouard, Les relations patronales-ouvrières dans lindustrie de la chaussure de la province do Québec.

YACCARINI, Benoît, Les tribunaux du travail. 